\title{
Obstructive sleep apnea and psychomotor vigilance task performance
}

\author{
This article was published in the following Dove Press journal: \\ Nature and Science of Sleep \\ 23 May 2014 \\ Number of times this article has been viewed
}

\author{
Salma Batool-Anwar' \\ Stefanos N Kales ${ }^{3,4}$ \\ Sanjay R Patel' \\ Vasileia Varvarigou ${ }^{3}$ \\ Pamela N DeYoung ${ }^{2}$ \\ Atul Malhotra ${ }^{2}$ \\ 'Department of Medicine, Sleep \\ Disorders Program, Brigham and \\ Women's Hospital, Boston, MA, USA; \\ 2Pulmonary Critical Care Division, \\ University of California San Diego, \\ La Jolla, CA, USA; ${ }^{3}$ Department of \\ Environmental and Occupational \\ Medicine and Epidemiology, Harvard \\ School of Public Health, Boston, \\ ${ }^{4}$ Department of Occupational \\ Medicine, The Cambridge Health \\ Alliance, Cambridge, MA, USA
}

Background: Obstructive sleep apnea (OSA) is a highly prevalent disorder with considerable morbidity and mortality. Vigilance and attentiveness are often impaired in OSA patients. In occupational medicine settings, subjective reports of sleepiness are notoriously inaccurate, making the identification of objective measures of vigilance potentially important for risk assessments of fitness for duty. In order to evaluate the effects of OSA on attentiveness and vigilance, we conducted a cross-sectional study to examine the association between OSA and psychomotor vigilance task (PVT) performance.

Methods: Patients attending sleep clinics for evaluation of possible sleep apnea were recruited. The subjects underwent either a standard overnight laboratory polysomnography or home sleep study. Subjective daytime sleepiness was assessed by Epworth sleepiness scale, and vigilance was tested using a portable device. The participants were asked to respond to the PVT signals using their dominant hand. Each PVT administration lasted 10 minutes, with stimuli signals appearing randomly at variable intervals of 2-10 seconds.

Results: Mean age of the participants was $46 \pm 15$ years, and mean body mass index was $34.3 \pm 9.8 \mathrm{~kg} / \mathrm{m}^{2}$. Participants with higher Epworth scores had worse PVT performance $(P<0.05)$. In multivariate analyses, age, body mass index, and poor sleep efficiency (measured by Pittsburgh sleep quality index score) were associated with worse PVT performance $(P<0.05)$. In contrast, PVT performance did not differ significantly across categories of apnea hypopnea index severity. Subgroup analysis demonstrated that women had worse performance on all PVT measures $(P<0.05)$.

Conclusion: PVT performance can be utilized for risk assessments of sleepiness and may be particularly useful among populations where subjective reports are unreliable.

Keywords: obstructive sleep apnea, psychomotor vigilance test, sleepiness

\section{Introduction}

Obstructive sleep apnea (OSA) is a highly prevalent disorder with considerable morbidity and mortality. Epidemiologic studies have linked OSA with cardiometabolic disorders as well as motor vehicle crashes. Studies have suggested up to a sevenfold increase in crashes in patients with OSA. ${ }^{1}$ OSA prevalence is likely rising due to the aging of the population and the obesity epidemic. Moreover, the prevalence of OSA among high-risk occupations, such as commercial drivers, is thought to be even higher than in the general population. ${ }^{2,3}$ Microarousals and oxygen desaturation among patients with OSA have been linked to excessive daytime sleepiness and decreases in attention contributing to motor vehicle crash risk. ${ }^{4}$ However, the lack of clinical or polysomnographic characteristics that identify patients at higher risk of crash makes it difficult for
Correspondence: Salma Batool-Anwar Department of Medicine, Sleep Disorders Program, Brigham and Women's Hospital, 22I Longwood Avenue, Boston, MA BLI 02II5, USA

Tel + I 6177325033

Fax + I 6177327337

Email sbatool@bics.bwh.harvard.edu 
clinicians to predict which OSA patients should be prioritized for therapy and when they should be restricted from complex safety sensitive tasks such as driving. The situation is especially difficult among commercial drivers, who either are unaware or minimize their impairment. Additionally, there is only a weak correlation between sleep apnea severity or oxygen desaturation and the risk for motor vehicle crash. ${ }^{5}$ Currently, commercial driver medical examinations rely primarily on subjective self-reports of sleepiness and other symptoms despite their being notoriously unreliable. Thus, the identification of objective measures of sleepiness and vigilance in OSA patients is critical to identify which patients may be at higher risk of complications.

Vigilance, a state of heightened readiness to perform efficiently, is thought to be impaired in patients with sleep apnea. ${ }^{6,7}$ The psychomotor vigilance task (PVT) is sensitive to sleep deprivation and is widely used as an objective tool to identify cognitive impairment in a variety of situations, such as sleep restriction, napping, and sleepiness. ${ }^{6-8}$ In an attempt to identify clinical parameters associated with vigilance in OSA patients at potential risk for motor vehicle crash, we conducted a cross-sectional study of PVT performance in a sleep clinic-derived OSA population.

We hypothesized that greater daytime sleepiness in patients with untreated sleep apnea would be associated with worse performance on PVT. Ultimately, our goal would be to develop simple, objective tools in occupational clinics to identify persons at higher risk for impairment during safety sensitive tasks such as driving.

\section{Materials and methods}

Between January 2011 and December 2011, all eligible patients ( $\geq 18$ years of age) referred to our sleep clinics for evaluation of possible sleep apnea were approached for this study when a research technician was available. A total of 100 subjects consented. Exclusion criteria were 1) use of stimulants (eg, amphetamines, modafinil), 2) known head injury, 3) dementia or retardation, 4) alcohol or drug abuse, and 5) pregnancy. Prior to participation, all subjects provided written informed consent. The study protocol was approved by the Partners' Institutional Review Board of the Brigham and Women's hospital.

\section{Sleep evaluation}

The subjects underwent either a standard clinical overnight in-laboratory polysomnography (electroencephalogram, electrooculogram, chin and anterior tibial electromyogram, electrocardiogram, airflow using nasal pressure and oronasal thermistor, respiratory excursions using inductance plethysmography, and pulse oximetry) or a home sleep study. Respiratory events were scored blindly using Chicago criteria ${ }^{9}$ (hypopneas were defined as a $>50 \%$ reduction in airflow from the baseline value lasting $>10$ seconds and associated with a $3 \%$ desaturation or arousal. Apneas were defined as the absence of airflow lasting $>10$ seconds). Apnea hypopnea index (AHI) was defined as the number of apneas and hypopneas per hour of sleep. The severity of sleep apnea was ranked as mild, moderate, or severe based on AHI categories $(5-<15,15-30$, and $>30)$.

Sleep quality was assessed using the Pittsburgh sleep quality index (PSQI). The PSQI is a commonly used and validated instrument that provides a self-assessed measure of sleep disturbance and sleep quality over the preceding month. Nineteen items provide ratings on subjective sleep quality, sleep latency, sleep duration, habitual sleep efficiency, sleep disturbances, use of sleeping medication, and daytime dysfunction. ${ }^{10}$

Clinical characteristics including body mass index (BMI) and neck circumference were measured by an experienced medical assistant naïve to the goals of the research study.

\section{Daytime sleepiness evaluation}

All participants were evaluated for daytime sleepiness and vigilance using the Epworth sleepiness scale (ESS) and PVT, respectively. The subjects completed the questionnaire and performed PVT on the same day.

\section{Epworth sleepiness scale}

The ESS is a simple self-administered test and is used frequently to measure the subjective level of daytime sleepiness. ${ }^{11}$ It consists of eight items regarding the likelihood of dozing in sedentary situations that patients rate on a Likert scale. The simple questionnaire has been validated in previous studies, and a significant correlation was found between ESS scores and those of mean sleep latency tests $(r=-0.5, P<0.01)$. The ESS questionnaire was administered as part of the initial sleep clinic evaluation.

\section{Psychomotor vigilance task}

PVT has been demonstrated to be sensitive to sleep disruption and is regarded as an objective measure of vigilance in a variety of experimental conditions..$^{6-8}$ The current study utilized a portable device (Model PVT-192; CWE, Inc., Ardmore, PA, USA) based on the original test described in 1985 by Dinges and Powel ${ }^{12}$ (microcomputer analysis). The participants sat in a closed and quiet examination room, without any auditory or visual disturbance. A 1-minute mock PVT demonstration was done prior to each test. The PVT 
Table I Baseline characteristics of study participants according to apnea hypopnea index categories

\begin{tabular}{|c|c|c|c|c|}
\hline \multirow[t]{2}{*}{ Variables } & \multicolumn{4}{|c|}{ Apnea hypopnea index } \\
\hline & $\begin{array}{l}<5 / \text { hour } \\
n=18\end{array}$ & $\begin{array}{l}5-15 / \text { hour } \\
n=19\end{array}$ & $\begin{array}{l}15-30 / \text { hour } \\
n=10\end{array}$ & $\begin{array}{l}>30 / \text { hour } \\
n=14\end{array}$ \\
\hline Age years, mean (SD) & $42.9(15.5)$ & $52.0(14.6)$ & $47.0(10.9)$ & $52.0(16.9)$ \\
\hline Males, n (\%) & $9(50)$ & II (58) & $7(70)$ & II (79) \\
\hline BMI kg/m², median (QI, Q3)* & $32.0(27,39)$ & $31.5(26,35)$ & $32.6(31,36)$ & $37.0(33,42)$ \\
\hline ESS, mean (SD) & $10(4)$ & $8.9(6.5)$ & $11.9(6.1)$ & I2.I (5.6) \\
\hline $\begin{array}{l}\text { Neck circumference inches, } \\
\text { median (QI, Q3)* }\end{array}$ & $15(14,17)$ & $16(14,17)$ & $16(15,18)$ & $18(17,20)$ \\
\hline Hypertension, n (\%) & 7 (39) & $7(4 I)$ & $2(20)$ & $10(7 I)$ \\
\hline PSQI score, mean (SD) & $8.2(3.0)$ & $8.8(4.4)$ & $6.8(2.5)$ & $8.1(5.5)$ \\
\hline
\end{tabular}

Note: *Represents quartile I and 3.

Abbreviations: BMI, body mass index; ESS, Epworth sleepiness scale; PSQI, Pittsburgh sleep quality index; SD, standard deviation.

visual display was held 14-22 inches from the subject's eyes. The participants were asked to either use the index finger or thumb of their dominant hand to respond to the PVT signals. The participants were instructed to maintain the fastest possible reaction times to a simple visual stimulus: a red lightemitting diode displaying time in milliseconds in a window of the portable PVT device. Each PVT administration lasted 10 minutes, during which the stimuli randomly appeared at variable intervals of $2-10$ seconds.

Based on previous research on PVT, we included the following outcome measures of PVT performance: 1) mean reaction time (RT), 2) mean I/RT (reciprocal response time or response speed), 3) slowest 10\% I/RT, 4) fastest $10 \%$ of RT, and 5) number of lapses, defined as RT $>500$ milliseconds (errors of omission). Responses were considered valid if the RT was $>100$ milliseconds. Responses without a stimulus or RT $<100$ milliseconds were counted as false starts (errors of commission).

\section{Statistical analysis}

Statistical analysis was performed using Stata software, version 11 (StataCorp, College Station, TX, USA). Univariate and multivariate logistic regression models were used to assess the ability of hypothesized variables to predict lack of attention or poor performance. The distributions were examined graphically, and non-normally distributed variables were natural log or square root transformed. In the multiple regression analysis, we examined the association between PVT performance and the following: OSA severity as measured by AHI, sleepiness as assessed by ESS, age, BMI, sex, and PSQI global score. Statistical significance was set at a $P$-value $<0.05$, two-tailed.

\section{Results}

Table 1 demonstrates the clinical and anthropometric parameters among the participants stratified according to AHI categories. Mean age of the participants was $46 \pm 15$ years. The majority of the participants in the higher AHI category ( $>30$ /hour) were male and obese (median BMI was $37 \mathrm{~kg} / \mathrm{m}^{2}$ with $25 \%$ and $75 \%$ being $33 \mathrm{~kg} / \mathrm{m}^{2}$ and $42 \mathrm{~kg} / \mathrm{m}^{2}$, respectively). Similar trends were noted after stratification by ESS categories (Table 2). The mean PSQI global score for the cohort was 7.9, suggesting poor sleep prior to testing.

PVT performance variables according to AHI category are shown in Table 3. Participants in the AHI category 15-30/hour had prolonged mean reaction times; however, this observation was not statistically significant. In contrast, significantly worse PVT performance was noted among participants who reported high ESS scores $(P=0.04)$ (Table 4). The mean of the slowest $10 \%$ of RT was prolonged among participants with ESS score $>9(P<0.05)$. In the univariate regression model (Table 5), a statistically significant association was observed between age and various PVT variables. In the same model, higher BMI, AHI, ESS, and PSQI were significantly associated with poorer performance on PVT. In addition, a marginally significant association was noted among ESS and PVT lapses $(P=0.05)$. Table 6 presents the

Table 2 Baseline characteristics of study participants according to Epworth sleepiness scale categories

\begin{tabular}{|c|c|c|}
\hline & $\begin{array}{l}\text { ESS } \leq 9 \\
n=25\end{array}$ & $\begin{array}{l}\text { ESS }>9 \\
\mathrm{n}=36\end{array}$ \\
\hline Age years, mean (SD) & $46.6(17.5)$ & $49.9(13)$ \\
\hline Males, n (\%) & $16(64)$ & $22(6 \mathrm{I})$ \\
\hline BMI kg/m², median (QI, Q3)* & $32.3(29.0,39.2)$ & $33.2(27.0,38.0)$ \\
\hline $\mathrm{AHI}$, median $(\mathrm{Q}, \mathrm{Q} 3)^{*}$ & $9(5,23)$ & $13(4,29)$ \\
\hline $\begin{array}{l}\text { Neck circumference inches, } \\
\text { median (QI, Q3)* }\end{array}$ & $16.0(14.5,17.5)$ & $16.0(15.0,18.0)$ \\
\hline Hypertension, n (\%) & $9(37.5)$ & $17(48.6)$ \\
\hline PSQI score, mean (SD) & $8.1(4.2)$ & $8.2(3.9)$ \\
\hline
\end{tabular}

Note: *Represents quartile I and 3.

Abbreviations: AHI, apnea hypopnea index; BMI, body mass index; ESS, Epworth sleepiness scale; PSQI, Pittsburgh sleep quality index; SD, standard deviation. 
Table 3 Psychomotor vigilance task performance by the apnea hypopnea index categories

\begin{tabular}{|c|c|c|c|c|c|}
\hline \multirow[t]{3}{*}{ PVT variables } & \multicolumn{4}{|c|}{ AHI categories } & \multirow[t]{3}{*}{$P$-value } \\
\hline & $<\mathbf{5 / h r}$ & $5-15 / h r$ & I5-30/hr & $>\mathbf{3 0}$ & \\
\hline & $n=18$ & $n=19$ & $n=10$ & $n=14$ & \\
\hline $\mathrm{RT}(\mathrm{ms})^{*}$ & $283(37)$ & $265(47)$ & $286(49)$ & $265(34)$ & 0.37 \\
\hline Fastest I0\% RT (ms)* & $209(2 I)$ & $194(25)$ & $209(24)$ & $200(23)$ & 0.18 \\
\hline Slowest I0\% RT (ms)* & $451(164)$ & $453(182)$ & $492(184)$ & 407 (88) & 0.64 \\
\hline I/slowest I0\% RT (ms)* & $2.5(0.45)$ & $2.6(0.6 I)$ & $2.4(0.69)$ & $2.6(0.4 I)$ & 0.70 \\
\hline I/RT (ms)* & $3.7(0.42)$ & 4.I (0.59) & $3.8(0.54)$ & $3.9(0.42)$ & 0.17 \\
\hline Lapses $(\mathrm{RT}>500 \mathrm{~ms}) * *$ & $0.9(0.92)$ & $0.97(0.91)$ & $\mathrm{I} .4(\mathrm{I} . \mathrm{I})$ & $0.68(0.8 \mathrm{I})$ & 0.34 \\
\hline False start $(\mathrm{RT}<100 \mathrm{~ms}){ }^{* *}$ & $0.9(1.3)$ & $0.93(1.0)$ & $0.59(1.0)$ & I.3 (I.I) & 0.48 \\
\hline
\end{tabular}

results of multivariable regression analysis of PVT variables adjusting for age, BMI, AHI, ESS, PSQI score, and sex. In this model, age was significantly related to poor performance on all of the PVT variables $(P<0.05)$. Similarly, a significant association was found between slowest $10 \% \mathrm{RT}$, lapses, and BMI $(P<0.05)$. In addition, poor PVT performance was also noted among participants with poor sleep quality as measured by PSQI. However, a marginally significant association was found between ESS and PVT variables in this model. Subgroup univariate analysis suggested that compared to men, women had significantly worse performance on all PVT measures $(P<0.05)$ (data not shown). However, adding sex to the full multiregression model did not change the results.

\section{Discussion}

The current study sought to identify clinical parameters associated with vigilance in a sleep clinic-derived OSA population. The main findings of this cross-sectional study were that poor sleep quality as measured by PSQI score,

Table 4 Psychomotor vigilance task performance by Epworth sleepiness score categories

\begin{tabular}{|c|c|c|c|}
\hline \multirow[t]{2}{*}{ PVT variables } & \multicolumn{2}{|c|}{ ESS categories } & \multirow[t]{2}{*}{$P$-value } \\
\hline & $\begin{array}{l}\leq 9 \\
n=25\end{array}$ & $\begin{array}{l}>9 \\
n=36\end{array}$ & \\
\hline $\mathrm{RT}(\mathrm{ms})^{*}$ & $260(27)$ & $283.4(48)$ & 0.04 \\
\hline Fastest $10 \%$ RT $(\mathrm{ms})^{*}$ & $198(20)$ & $204(25)$ & 0.27 \\
\hline Slowest I0\% RT (ms)* & $396(100)$ & $485(181)$ & 0.03 \\
\hline I/slowest I0\% RT (ms)* & $2.8(0.42)$ & $2.4(0.57)$ & 0.01 \\
\hline $\mathrm{I} / \mathrm{RT}(\mathrm{ms})^{*}$ & $4.03(0.4 I)$ & $3.8(0.55)$ & 0.11 \\
\hline Lapses $(\mathrm{RT}>500 \mathrm{~ms}) * *$ & $0.6(0.73)$ & $1.2(1.0)$ & 0.03 \\
\hline False start $(\mathrm{RT}<100 \mathrm{~ms})^{* *}$ & $0.86(I . I)$ & $\mathrm{I}(\mathrm{I} . \mathrm{I})$ & 0.62 \\
\hline
\end{tabular}

Notes: *Log transformed; **square root transformed; PVT variables represent back transformation after log/square root transformation; Bold $P$-values represent statistical significance. All PVT variable data is presented as mean (SD).

Abbreviations: ESS, Epworth sleepiness scale; I/RT, reciprocal response time; 1/slowest, reciprocal of slowest response time; ms, milliseconds; PVT, psychomotor vigilance task; $\mathrm{RT}$, reaction time; $\mathrm{SD}$, standard deviation. and subjective sleepiness as measured by the ESS, were associated with poor PVT performance, while OSA severity as categorized by AHI was not associated with variation in PVT measures. The findings of this study are consistent with previous literature demonstrating an association between lack of sleep and poor PVT performance. ${ }^{13,14}$ Studies have also demonstrated weak but significant correlations between the ESS and the risk of motor vehicle accident. ${ }^{4,15} \mathrm{~A}$ twofold increase in the risk of accidents among drivers with sleepiness as measured by ESS has also been reported in another study by Howard et al. ${ }^{3}$ Similarly, elevated ESS scores were found among drivers with crashes. ${ }^{16}$

Although ESS has been shown to have an association with motor vehicle crashes, studies have reported that many patients do not subjectively report impaired vigilance..$^{17,18}$ In particular, self-reported questionnaires are not reliable in assessing the degree of sleepiness, particularly in occupational settings. ${ }^{19}$ Parks et al demonstrated that among commercial drivers at high-risk for OSA, $85 \%$ denied snoring or daytime sleepiness ${ }^{20}$ when asked during medical certification examinations for driving. Thus, PVT may have diagnostic utility as an objective tool, particularly in settings where subjective reporting may be unreliable.

The current study did not find any significant association between OSA severity as measured by AHI and vigilancerelated PVT performance. These results are consistent with previously published studies where OSA severity was found to be unrelated to the PVT performance. ${ }^{7,21}$ While OSA has been shown to increase the risk of accidents, it is not clear which OSA patients are at increased risk. Gozal et al have suggested differential susceptibility to the impact of sleep disturbance, perhaps on a genetic basis. ${ }^{22}$ The cutoff levels of severity for AHI are arbitrary and have been a source of controversy. Moreover, it has been suggested that there is only weak correlation between the $\mathrm{AHI}$ and the risk of motor 
Table 5 Univariate regression models predicting psychomotor vigilance task variables

\begin{tabular}{|c|c|c|c|c|c|c|}
\hline & Age (years) & BMI $\left(\mathrm{kg} / \mathrm{m}^{2}\right)$ & ESS & PSQI & Arousal index & $\begin{array}{l}\text { AHI (eventsl } \\
\text { hour) }\end{array}$ \\
\hline & $R^{2}$ (P-value) & $R^{2}$ (P-value) & $\overline{R^{2} \text { (P-value) }}$ & $\overline{R^{2}(P \text {-value })}$ & $R^{2}$ (P-value) & $R^{2}(P$-value $)$ \\
\hline $\mathrm{RT}^{*}(\mathrm{~ms})$ & $0.13(0.001)$ & $0.03(0.12)$ & $0.04(0.16)$ & $0.11(0.01)$ & $0.04(0.03)$ & $0.02(0.03)$ \\
\hline $\mathrm{I} / \mathrm{RT}^{*}(\mathrm{~ms})$ & $0.09(0.015)$ & $0.01(0.35)$ & $0.03(0.24)$ & $0.14(0.003)$ & $0.04(0.05)$ & $0.02(0.05)$ \\
\hline Fastest 10\% RT* (ms) & $0.05(0.09)$ & $0.004(0.61)$ & $0.009(0.47)$ & $0.11(0.009)$ & $0.02(0.11)$ & $0.03(0.04)$ \\
\hline Slowest I0\% RT* (ms) & $0.18(<0.001)$ & $0.09(\mathbf{0 . 0 0 5 )}$ & $0.06(0.07)$ & $0.03(0.25)$ & $0.03(0.19)$ & $0.01(0.12)$ \\
\hline I/slowest I0\% RT* (ms) & $0.15(<\mathbf{0 . 0 0 0 1})$ & $0.08(0.01)$ & $0.07(0.07)$ & $0.07(0.06)$ & $0.04(0.02)$ & $0.01(0.17)$ \\
\hline Lapses** (RT > $500 \mathrm{~ms})$ & $0.15(<0.0001)$ & $0.16(<0.0001)$ & $0.07(0.05)$ & $0.01(0.4)$ & $0.003(0.7)$ & $0.007(0.34)$ \\
\hline False starts** $(\mathrm{RT}<100 \mathrm{~ms})$ & $0.08(0.03)$ & $0.02(0.23)$ & $0.001(0.9)$ & $0.001(0.9)$ & $0.01(0.6)$ & $0.01(0.6)$ \\
\hline
\end{tabular}

Notes: *Log transformed; **square root transformed; Bold P-values represent statistical significance.

Abbreviations: AHI, apnea hypopnea index; BMI, body mass index; ESS, Epworth sleepiness scale; I/RT, reciprocal response time; I/slowest, reciprocal of slowest response time; ms, milliseconds; PSQI, Pittsburgh sleep quality index (global) score; RT, reaction time; SD, standard deviation.

vehicle crash, ${ }^{5}$ as these rare events are likely multifactorial and thus hard to predict. In addition, treatment of sleepdisordered breathing has been shown to reduce the risk of accidents. ${ }^{23}$ Thus, considering the risks and costs associated with motor vehicle crashes related to sleep-disordered breathing, it is crucial to identify OSA patients with impaired vigilance and enforce treatment of high-risk patients. This goal is of particular importance for commercial drivers and those involved in safety sensitive jobs.

Our study extends the results of previously published studies demonstrating decrements in PVT performance with high BMI. ${ }^{7,24,25}$ Obesity has also been shown to increase the risk of motor vehicle crashes. ${ }^{26,27}$ It has been proposed that obese patients have difficulty moving easily in the driver's seat, leading to reduced ability to see traffic approaching from the back or side. ${ }^{26}$ More importantly, increases in the level of inflammatory mediators within adipose tissues have been shown to reduce vigilance and increase sleepiness. ${ }^{28}$

Finally, our study suggests that the magnitude of PVT impairment varies with sex, confirming previously published results. ${ }^{29}$ We found statistically significant differences in PVT performance, with poor performance among women. The reasons for this sex difference are not clear, but perhaps reflect increased experience with electronic media such as video games among males over females.

Despite our study's strengths, we acknowledge a number of limitations. First, we did not have a healthy control group since the subjects were all enrolled in a sleep clinic. As such, the performance on PVT may be better in nonclinical populations. However, because our goal was to define a method of defining risk among potentially susceptible clinic patients, we believe we have made the relevant comparisons in the present study. However, we acknowledge that we cannot address whether clinical OSA patients perform better or worse than healthy controls from the community. Second, our cross-sectional design and our sample size did not allow us to assess prospectively risk of subsequent motor vehicle accidents, which are fairly rare events. Thus, we cannot draw any rigorous conclusions about whether we can actually predict accidents or not. Moreover, our study was not

Table 6 Multiple regression model

\begin{tabular}{|c|c|c|c|c|c|c|}
\hline & Age (years) & BMI $\left(\mathrm{kg} / \mathrm{m}^{2}\right)$ & ESS & PSQI & AHI (events/hour) & Sex \\
\hline $\mathrm{RT}^{*}(\mathrm{~ms})$ & $\begin{array}{l}-0.003 \\
(-0.01 \text { to }-0.002) \\
\mathbf{0 . 0 1}\end{array}$ & $\begin{array}{l}0.001 \\
(-0.004-0.004)\end{array}$ & $\begin{array}{l}0.005 \\
(-0.00 I-0.01)\end{array}$ & $\begin{array}{l}0.01 \\
(0.0003-0.02) \\
\mathbf{0 . 0 5 5}\end{array}$ & $\begin{array}{l}-0.0005 \\
(-0.0002-0.02)\end{array}$ & $\begin{array}{l}-0.05 \\
(-0.14-0.02)\end{array}$ \\
\hline $\begin{array}{l}\text { Slowest 10\% } \\
\mathrm{RT}^{*}(\mathrm{~ms})\end{array}$ & $\begin{array}{l}0.007 \\
(-0.01-0.01) \\
\mathbf{0 . 0 0 5}\end{array}$ & $\begin{array}{l}-0.0 \mathrm{I} \\
(-0.0 \mathrm{I}-0.00 \mathrm{I})\end{array}$ & $\begin{array}{l}-0.01 \\
(-0.1 \text { to }-0.01) \\
\mathbf{0 . 0 6}\end{array}$ & $\begin{array}{l}0.01 \\
(-0.01-0.03)\end{array}$ & $\begin{array}{l}0.0005 \\
(-0.002-0.001)\end{array}$ & $\begin{array}{l}0.06 \\
(0.21-0.09)\end{array}$ \\
\hline $\mathrm{I} / \mathrm{RT}^{*}(\mathrm{~ms})$ & $\begin{array}{l}-0.002 \\
(-0.004-0.000 I) \\
\mathbf{0 . 0 4 5}\end{array}$ & $\begin{array}{l}-0.001 \\
(-0.005-0.003)\end{array}$ & $\begin{array}{l}-0.004 \\
(-0.01-0.002)\end{array}$ & $\begin{array}{l}-0.01 \\
(-0.02 \text { to }-0.002) \\
\mathbf{0 . 0 3}\end{array}$ & $\begin{array}{l}0.0004 \\
(-0.0004-0.001)\end{array}$ & $\begin{array}{l}0.06 \\
(-0.01 \text { to }-0.13)\end{array}$ \\
\hline $\begin{array}{l}\text { Lapses** } \\
(\mathrm{RT}>500 \mathrm{~ms})\end{array}$ & $\begin{array}{l}0.02 \\
(0.01-0.03) \\
\mathbf{0 . 0 0 8}\end{array}$ & $\begin{array}{l}-0.04 \\
(-0.07 \text { to }-0.01) \\
\mathbf{0 . 0 0 6}\end{array}$ & $\begin{array}{l}0.04 \\
(-0.003 \text { to }-0.08) \\
\mathbf{0 . 0 7}\end{array}$ & $\begin{array}{l}0.01 \\
(-0.05-0.07)\end{array}$ & $\begin{array}{l}0.001 \\
(-0.007-0.01)\end{array}$ & $\begin{array}{l}0.12 \\
(0.68-0.43)\end{array}$ \\
\hline
\end{tabular}

Notes: *Log transformed; **square root transformed; Bold $P$-values represent statistical significance.

Abbreviations: AHI, apnea hypopnea index; BMI, body mass index; ESS, Epworth sleepiness scale; I/RT, reciprocal response time; ms, milliseconds; PSQI, Pittsburgh sleep quality index (global) score; RT, reaction time. 
performed in commercial drivers although such a study is ongoing with our collaborators. Third, our study was crosssectional, and thus we did not assess response to therapy. Thus, we do not have data regarding the reversibility of the observed abnormalities. Finally, lack of strong association between ESS and PVT variables in the multiple regression model could be related to small sample size or also that higher ESS is associated with increasing BMI and age, and therefore, was no longer significant when these factors were considered together, underscoring the need for an objective tool to assess daytime sleepiness.

Despite these limitations, we believe our paper adds importantly to the existing literature and is worth pursuing in further research.

In summary, psychomotor vigilance testing performance is associated with sleepiness as measured by ESS, and therefore may be of value as a risk assessment tool in populations where subjective reports are unreliable.

\section{Disclosure}

Dr Kales reports serving as paid expert witness and independent medical examiner, including cases involving commercial drivers. Dr Kales has consulted with Circadies. Dr Malhotra reports having received consulting and/or research grant income from National Institutes of Health, American Heart Association, Philips, Sleep Group Solutions, Sleep HealthCenters, Pfizer, Apnex, Apnicure but has relinquished all outside personal income since May 2012. The other authors report no conflicts of interest in this work.

\section{References}

1. Terán-Santos J, Jiménez-Gómez A, Cordero-Guevara J. The association between sleep apnea and the risk of traffic accidents. Cooperative Group Burgos-Santander. N Engl J Med. 1999;340(11):847-851.

2. Pack AI, Maislin G, Staley B, et al. Impaired performance in commercial drivers: role of sleep apnea and short sleep duration. Am J Respir Crit Care Med. 2006;174(4):446-454.

3. Howard ME, Desai AV, Grunstein RR, et al. Sleepiness, sleep-disordered breathing, and accident risk factors in commercial vehicle drivers. $\mathrm{Am} \mathrm{J}$ Respir Crit Care Med. 2004;170(9):1014-1021.

4. Mazza S, Pépin JL, Naëgelé B, Plante J, Deschaux C, Lévy P. Most obstructive sleep apnoea patients exhibit vigilance and attention deficits on an extended battery of tests. Eur Respir J. 2005;25(1):75-80.

5. Barbé F, Pericás J, Muñoz A, Findley L, Antó JM, Augustí AG. Automobile accidents in patients with sleep apnea syndrome. An epidemiological and mechanistic study. Am J Respir Crit Care Med. 1998;158(1): $18-22$.

6. Belenky G, Wesensten NJ, Thorne DR, et al. Patterns of performance degradation and restoration during sleep restriction and subsequent recovery: a sleep dose-response study. J Sleep Res. 2003;12(1):1-12.

7. Lee IS, Bardwell WA, Ancoli-Israel S, Dimsdale JE. Number of lapses during the psychomotor vigilance task as an objective measure of fatigue. J Clin Sleep Med. 2010;6(2):163-168.

8. Philip P, Sagaspe P, Moore N, et al. Fatigue, sleep restriction and driving performance. Accid Anal Prev. 2005;37(3):473-478.
9. The Report of an American Academy of Sleep Medicine Task Force. Sleep-related breathing disorders in adults: recommendations for syndrome definition and measurement techniques in clinical research. Sleep. 1999;22(5):667-689.

10. Buysse DJ, Reynolds CF, Monk TH, Berman SR, Kupfer DJ. The Pittsburgh Sleep Quality Index: a new instrument for psychiatric practice and research. Psychiatry Res. 1989;28(2):193-213.

11. Johns MW. A new method for measuring daytime sleepiness: the Epworth sleepiness scale. Sleep. 1991;14(6):540-545.

12. Dinges DF, Powell JW. Microcomputer analyses of performance on a portable, simple visual RT task during sustained operations. Behavior Research Methods, Instruments and Computers. 1985;17(6):652-655.

13. Dinges DF, Pack F, Williams K, et al. Cumulative sleepiness, mood disturbance and psychomotor vigilance performance decrements during a week of sleep restricted to 4-5 hours per night. Sleep. 1997; 20(4)267-277.

14. Doran SM, Van Dongen HP, Dinges DF. Sustained attention performance during sleep deprivation: evidence of state instability. Arch Ital Biol. 2001;139:253-267.

15. Noda A, Yagi T, Yokota M, et al. Daytime sleepiness and automobile accidents in patients with obstructive sleep apnea syndrome. Psychiatry and Clin Neurosci. 1998;52(2)221-222.

16. Stutts JC, Wilkins JW, Scott Osberg J, Vaughn BV. Driver risk factors for sleep-related crashes. Accid Anal Prev. 2003;35(3):321-331.

17. Kingshott RN, Engleman HM, Deary IJ, Douglas NJ. Does arousal frequency predict daytime function? Eur Respir J. 1998;12(6): 1264-1270.

18. Walter TJ, Foldvary N, Mascha E, Dinner D, Golish J. Comparison of Epworth Sleepiness Scale scores by patients with obstructive sleep apnea and their bed partners. Sleep Med. 2002;3(1):29-32.

19. Dagan Y, Doljansky JT, Green A, Weiner A. Body Mass Index (BMI) as a first-line screening criterion for detection of excessive daytime sleepiness among professional drivers. Traffic Inj Prev. 2006;7(1): 44-48.

20. Parks P, Durand G, Tsismenakis AJ, Vela-Bueno A, Kales S. Screening for obstructive sleep apnea during commercial driver medical examinations. J Occup Environ Med. 2009;51(3):275-282.

21. Barbé, Pericás J, Muñoz A, et al. Automobile accidents in patients with sleep apnea syndrome: an epidemiological and mechanistic study. Am J Respir Crit Care Med. 1998;158(1):18-22.

22. Gozal D, Capdevila OS, Kheirandish-Gozal L, McLaughlin Crabtree V. APOE $\varepsilon 4$ allele, cognitive dysfunction, and obstructive sleep apnea in children. Neurology. 2007;69(3):243-249.

23. Cassel W, Ploch T, Becker C, Dugnus D, Peter JH, von Wichert P. Risk of traffic accidents in patients with sleep-disordered breathing: reduction with nasal CPAP. Eur Respir J. 1996;9(12):2606-2611.

24. Kim H, Dinges DF, Young T. Sleep-disordered breathing and psychomotor vigilance in a community-based sample. Sleep. 2007;30(10):1309-1316.

25. Zhang C, Varvarigou V, Parks PD, et al. Psychomotor vigilance testing of professional drivers in the occupational health clinic: a potential objective screen for daytime sleepiness. J Occup Environ Med. 2012;54(3):296-302.

26. Mulgrew AT, Nasvadi G, Butt A, et al. Risk and severity of motor vehicle crashes in patients with obstructive sleep apnoea/hypopnoea. Thorax. 2008;63(6):536-541.

27. Anderson JE, Govada M, Steffen TK, et al. Obesity is associated with the future risk of heavy truck crashes among newly recruited commercial drivers. Accid Anal Prev. 2012;49:378-384.

28. Vgontzas AN, Papanicolaou DA, Bixler EO, et al. Sleep apnea and daytime sleepiness and fatigue: relation to visceral obesity, insulin resistance, and hypercytokinemia. J Clin Endocrinol Metab. 2000;85(3):1151-1158.

29. Blatter K, Graw P, Münch M, Knoblauch V, Wirz-Justice A, Cajochen C. Gender and age differences in psychomotor vigilance performance under differential sleep pressure conditions. Behav Brain Res. 2006;168(2):312-317. 
Nature and Science of Sleep

\section{Publish your work in this journal}

Nature and Science of Sleep is an international, peer-reviewed, open access journal covering all aspects of sleep science and sleep medicine, including the neurophysiology and functions of sleep, the genetics of sleep, sleep and society, biological rhythms, dreaming, sleep disorders and therapy, and strategies to optimize healthy sleep. The journal welcomes

original research, clinical \& epidemiological studies, reviews \& evaluations, case reports and extended reports. The manuscript management system is completely online and includes a very quick and fair peerreview system, which is all easy to use. Visit http://www.dovepress.com/ testimonials.php to read real quotes from published authors.

Submit your manuscript here: http://www.dovepress.com/nature-and-science-of-sleep-journal 